\title{
Conformidade entre testemunhas oculares: efeitos de falsas informações nos relatos criminais
}

\author{
Renan Benigno Saraiva - Universidade de Brasilia, Brasilia, Brasil \\ Fabio Iglesias - Universidade de Brasilia, Brasília, Brasil \\ Gabriel Fontenelle Micas - Universidade de Brasilia, Brasilia, Brasil \\ Clara Pires Nunes Araújo - Universidade de Brasilia, Brasilia, Brasil \\ Clara Correa Lima - Universidade de Brasília, Brasília, Brasil \\ Marcela de Vasconcelos Costa - Universidade de Brasília, Brasilia, Brasil
}

\begin{abstract}
Resumo
Este estudo investigou como informações falsas fornecidas a testemunhas oculares podem afetar a fidedignidade de seus relatos. Os participantes foram divididos em duas condições experimentais. Todos assistiram ao vídeo de um crime e responderam a um questionário sobre informações nele descritas. Em uma condição, os participantes preencheram o questionário individualmente e, em seguida, discutiram suas respostas com um confederado, que fornecia informações falsas ao participante. Após discutirem tais informações, os participantes eram requisitados a fazer um novo relato. Em outra condição, os participantes realizaram todo o procedimento individualmente, sem receberem informações falsas. O número de erros na presença do confederado foi maior quando comparado com a condição sem o confederado. São discutidos possíveis fatores que envolvem a distorção da memória por meio de conformidade, assim como implicações práticas dos resultados encontrados.

Palavras-chave: conformidade; testemunhas oculares; falsas memórias; influência social; psicologia social experimental.
\end{abstract}

\section{Conformity among eyewitnesses: effect of false information on criminal reports}

\begin{abstract}
The current study investigated how misinformation presented to eyewitnesses can affect the reliability of their reports. An experiment was conducted with 54 participants, divided in two conditions. All participants watched a video of a crime scene, and then answered a questionnaire about the content of the video. In one condition participants filled the questionnaire individually and then discussed their answers with a confederate, instructed to provide misinformation to participants. After the discussion participants were required to provide a new report. In another condition participants made the whole procedure individually, without receiving any misinformation. Mistakes in the presence of the confederate were higher when compared to the condition with no confederate. Potential factors underlying the distortion of memories through conformity, as well as practical implications of the results are discussed.

Keywords: conformity; eyewitnesses; false memories; social influence; experimental social psychology.
\end{abstract}

Conformidad entre testigos oculares: efectos de falsas informaciones en testimonios criminales

\begin{abstract}
Resumen
Este estudio investigó cómo información falsa proporcionada a testigos oculares puede afectar la veracidad de los testimonios. Los participantes fueron divididos en dos condiciones experimentales, y todos asistieron el video de un delito y luego respondieron a un cuestionario sobre la información contenida en el mismo. En un grupo los participantes completaron el cuestionario de forma individual y luego discutieron sus respuestas con un asociado que les proporcionaba informaciones falsas. Después de discutir esas informaciones se les solicitaba hacer un nuevo testimonio. En el otro grupo los participantes realizaron todo el procedimiento individualmente, sin recibir información falsa. El número de errores fue mayor en la presencia del asociado. Se discuten los posibles factores implicados en la distorsión de la memoria mediante la conformidad, así como las implicaciones prácticas de los resultados.

Palabras-clave: conformidad; testigos oculares; falsas memorias; influencia social; psicología social experimental.
\end{abstract}

\section{Introdução}

O desfecho de muitos processos criminais depende de testemunhas oculares, tanto nas etapas de investigação quanto nas audiências judiciais. É fato pouco controverso, entretanto, que tais relatos podem se tornar inacurados, por diversos fatores de caráter social, emocional e cognitivo (Perfect \& Lindsay, 2013).
Toda reconstrução de fatos testemunhados depende de processos mnemônicos, que não garantem réplicas da realidade e, muitas vezes, carecem de fidedignidade. Ainda mais problemático, esses processos podem facilmente dar origem a falsas memórias (Stein, 2010). Destaca-se que erros cometidos por testemunhas oculares se tornaram o principal motivo para a prisão injusta de inocentes (Huff, Rattner, \& Sagarin, 1996), 
que foram, na maioria das vezes, inocentados posteriormente com evidências baseadas em DNA (Connors, Lundregan, Miller, \& McEwen, 1996).

O experimento pioneiro de Loftus e Palmer (1974) sobre o efeito de informações após o evento (IAE) marcou o início da popularidade de se investigar o problema do relato de testemunhas oculares, gerando programas sistemáticos de pesquisa sobre falsas memórias em diversos contextos de aplicação. Esse estudo evidenciou que a memória para eventos é muito flexível, suscetível a alterações por meio de informações sugestivas. Wright e Davies (1999) sumarizam que, após presenciarem determinado crime, as testemunhas podem entrar em contato com IAE de três formas distintas. A primeira ocorre quando se fazem perguntas tendenciosas sobre o ocorrido, contaminando as respostas de quem está sendo inquerido. Tal situação é, particularmente, característica em inquéritos com crianças que, supostamente, sofreram abusos sexuais, por serem mais suscetíveis à influência dos interrogadores (Ceci \& Bruck, 1993). A segunda forma de contato com as IAE se dá por meio das reconstituições do evento. Em tais situações, os indivíduos passam a incorporar novas informações em seus relatos e a registrar nova versão do ocorrido, mesmo não sendo verdadeiras (Wright \& Stroud, 1998). Por fim, IAE podem ser apresentadas por outras pessoas, tais como outras testemunhas que presenciaram o mesmo evento. Nessa situação, elas podem acrescentar em seus relatos informações advindas até de relatos que contrariem suas informações iniciais (Gabbert, Memon, \& Allan, 2003).

Alguns autores defendem, por um lado, que informações obtidas por grupos de testemunhas oculares são mais acuradas e confiáveis quando comparadas a informações obtidas de uma única testemunha (Stephenson, Clark, \& Wade; 1986; Warnick \& Sanders, 1980; Yarmey $\&$ Morris, 1998). Tal premissa se baseia na expectativa de que diferentes relatos podem ser complementares, tendo em vista que, em uma situação natural, cada testemunha percebe o evento por diferentes perspectivas. Por outro lado, a interação entre testemunhas também pode fazer com que o relato final possua mais informações equivocadas - oriundas de processos de influência social - quando comparado com o relato obtido de apenas uma testemunha. (Gabbert et al, 2003; Mori \& Mori, 2008; Wright, Self, \& Justice, 2000). O objetivo desta pesquisa é replicar, conceitualmente, o efeito da sugestão de falsas informações na memória de indivíduos sobre uma cena de um crime, procurando ampliar a discussão acerca dos resultados encontrados nessa temática. Julga-se necessário, também, fomentar a produção de pesquisas dessa natureza no contexto brasileiro, tendo em vista que poucas investigações envolvendo a memória de testemunhas oculares são elaboradas nacionalmente (Stein, 2010).

\section{Influência social e conformidade no relato de testemunbas}

Desde os estudos seminais de Asch (1951, 1956) com o famoso paradigma de conformidade no julgamento do tamanho de linhas, uma vasta quantidade de pesquisas foi realizada sobre como informações provenientes de outras pessoas podem influenciar relatos perceptuais (Bond \& Smith, 1996; Hogg, 2010). Tal fenômeno se baseia em processos de influência social, que possuem um papel fundamental no comportamento humano, incluindo aspectos cognitivos, tais como julgamentos e recordações (Forgas \& Williams, 2001). De forma análoga, uma série de estudos foi realizada sobre como informações após o evento influenciam o relato de testemunhas oculares (Wright \& Loftus, 1998). Eles revelam que a memória para eventos pode ser facilmente distorcida por informações obtidas após o ocorrido, que são particularmente problemáticas quando apresentadas a grupos de testemunhas. Um consenso entre testemunhas sobre uma informação, mesmo que seja falsa, pode ser visto como um sinal de acurácia por investigadores e jurados.

Os paradigmas de conformidade usam tipicamente métodos que envolvem informações falsas inseridas em questionários de recordação (Hoffman, Granhag, Kwong See, \& Loftus, 2001) ou em que o experimentador revela respostas de outras testemunhas fictícias, mas sempre sem a possibilidade do participante discutir tais informações com outras testemunhas (Luus \& Wells, 1994). Novos estudos optaram por delineamentos com maior validade ecológica, com interações ao vivo de testemunhas oculares, por meio do uso de cenários mais realísticos (Roediger, Meade, \& Bergman, 2001).

Para investigar o processo de conformidade entre testemunhas oculares em contextos laboratoriais, é necessário que informações conflitantes sejam apresentadas aos participantes. Diversos estudos investigaram efeitos de conformidade em testemunhas oculares que observaram o mesmo evento de formas diferentes. Em alguns desses estudos, os participantes assistiram a versões distintas de vídeos que retratavam o mesmo evento, sem estar cientes de tal dualidade. Em um estudo conduzido por Gabbert, Memon e Allan (2003), por exemplo, foram utilizados dois vídeo de um evento, sendo que cada vídeo possuía apenas dois elementos 
destoantes, que foram vistos apenas por um dos participantes. Cada participante assistiu, individualmente, a uma das versões do vídeo, mas ambos foram levados a acreditar que haviam assistido ao mesmo vídeo. Uma proporção significativa $(71 \%)$ das testemunhas que discutiram o evento afirmou lembrar-se de elementos que não foram apresentados a eles, mas apenas ao outro participante. Wright, Self e Justice (2000), em um estudo semelhante, encontraram que as memórias iniciais para o evento eram relativamente acuradas, o que decaia após a discussão entre os participantes (que observaram estímulos ligeiramente distintos), evidenciando altos índices de conformidade.

O uso de confederados, também, é um procedimento regular em muitos estudos sobre conformidade e influência social. Nesse caso, eles agem como se estivessem convictos de suas respostas, quando, na verdade, estão apenas apresentando uma informação equivocada aos participantes ingênuos. Asch (1958) mostrou como seus participantes facilmente entravam em consenso com um grupo de confederados. Um exemplo de estudo sobre testemunhas oculares utilizando confederados incluiu um homem desconhecido em uma interação com uma criança (Goodman et al, 1998).

O método utilizado na presente pesquisa envolve tanto a apresentação de vídeos quanto a participação de confederados. A utilização de vídeos em pesquisas sobre testemunhas oculares tem sido recorrente, sendo que Pozzulo, Crescini e Panton (2008) argumentam que o grau de acurácia de indivíduos não difere, significativamente, utilizando simulações ao vivo ou por vídeos. Outro fator importante em pesquisas envolvendo testemunhas oculares e eventos que eliciam ansiedade é o tipo de informação a ser lembrada, que podem ser classificadas em centrais ou periféricas. Informações centrais envolvem quaisquer elementos ligados, diretamente, ao evento eliciador de ansiedade, tais como características físicas dos agressores e das vítimas. Informações periféricas dizem respeito a elementos não associados diretamente ao evento eliciador de ansiedade, tais como detalhes da cena e do ambiente. A distinção dessas informações é necessária, pois o desempenho de testemunhas oculares é diferenciado diante de tais elementos. Estudos apontam que a ativação de uma resposta emocional está relacionada com essa divergência (Christianson, 1992). Em eventos com maior carga emocional, o desempenho de testemunhas para aspectos centrais é melhor, quando comparado com eventos com menor carga emocional. No entanto, um evento que não possui tal carga emocional facilita a lembrança de aspectos periféricos (Brown, 2003). Essa relação se repete em experimentos laboratoriais (Ibabe \& Sporer, 2004), em pesquisas de memória com crimes reais (Christianson \& Hübinette, 1993) e em autobiografias de experiências traumáticas (Wessel \& Merckelbach, 1994). Luna e Migueles (2009) verificaram que tanto a memória para aspectos periféricos quanto a memória para aspectos centrais podem ser distorcidas por meio da sugestão de falsas informações. A quantidade e qualidade de informações centrais fornecidas por testemunhas são de maior interesse para um júri, entretanto, informações periféricas também possuem importância, uma vez que a quantidade de detalhes fornecida sobre um crime aumenta a credibilidade de um relato, mesmo se os detalhes não forem ligados diretamente à ação principal (Bell \& Loftus, 1989).

$\mathrm{Na}$ presente pesquisa, foi esperado que as falsas informações fornecidas por um confederado influenciassem negativamente os depoimentos dos participantes, resultando em relatos menos acurados. Quanto aos tipos de informação, era esperado que os participantes se lembrassem mais de informações centrais do que informações periféricas de um determinado crime, tendo em vista os recursos atencionais relacionados a esses elementos.

\section{Método}

\section{Participantes}

Participaram do experimento 54 estudantes universitários (29 mulheres), abordados nos corredores de uma universidade. Eles foram divididos em duas condições experimentais: condição controle $(n=30)$, em que deveriam fazer relatos individuais, sem a presença do confederado, e condição concordância $(n=24)$, em que, além de se fazer os relatos individuais, deveriam fazer um relato unificado com um confederado, após discutirem o que assistiram. A participação, no estudo, era inteiramente voluntária e confidencial.

\section{Instrumentos}

Para simular o papel realizado pelas testemunhas oculares o participante era convidado a assistir a um vídeo obtido no Youtube, com duração de 50 segundos, de uma cena de briga de rua. No início do vídeo, três homens discutem entre si de forma agressiva e, logo em seguida, passam a se agredir fisicamente. Enquanto a briga ocorre, outras pessoas se acercam do evento, sem interagir com os agressores. Ao final do vídeo, um 
indivíduo aparece para separar a briga e, em seguida, os agressores se afastam lentamente. Nenhum áudio foi apresentado durante a exibição do vídeo. A cena era projetada na parede de uma sala reservada para a coleta de dados, a uma distância de cerca de dois metros do participante, que permanecia sentado.

Um questionário foi elaborado com 10 perguntas sobre os elementos do vídeo, divididas igualmente entre questões mais centrais e mais periféricas (anexo 1). As perguntas sobre elementos centrais englobaram aspectos diretamente relacionados ao crime (ex.: "Quantas pessoas estavam brigando no início do vídeo?"), enquanto as perguntas sobre elementos periféricos abordaram detalhes do cenário em que ocorreu a briga (ex.: "A briga ocorreu em um local com vista para o mar?").

\section{Procedimentos}

Todos os participantes foram instruídos a assistir ao vídeo da briga de rua, com atenção aos seus elementos. O vídeo era exibido em uma sala reservada para coleta de dados. Na condição concordância, os participantes assistiram ao vídeo junto um confederado, que se passava por um participante ingênuo. No total, três pesquisadores atuaram como confederados, tomando-se o cuidado de que o confederado e o participante de cada sessão não se conhecessem. Na condição controle, os participantes assistiram ao vídeo individualmente, sem a presença do confederado. Nenhum dos participantes conhecia o vídeo que foi apresentado.

$\mathrm{Na}$ condição concordância, imediatamente após o término do vídeo, o participante e o confederado eram separados, sendo instruídos a responderem ao questionário referente ao crime de forma individual. Após esse primeiro preenchimento, era requisitado que o participante e o confederado discutissem conjuntamente as perguntas do questionário, dessa vez preenchendo o questionário coletivamente, entrando em um consenso nas respostas. Nesse momento, o confederado fornecia informações incorretas para quatro das perguntas, sendo duas centrais e duas periféricas. Caso o participante não concordasse com as respostas, o confederado não deveria insistir na falsa informação. $\mathrm{Na}$ condição controle, o questionário era respondido apenas uma vez de forma individual, imediatamente após a visualização do vídeo. Ao final do procedimento, foi esclarecido aos participantes o objetivo da pesquisa, sendo explicado, na condição concordância, a atuação do confederado, e garantindo que o participante não havia desconfiado da encenação durante o procedimento.
Dentre as informações falsas fornecidas pelo confederado, as duas referentes a elementos centrais merecem um melhor detalhamento, por envolverem elementos de maior interesse em investigações policiais. $\mathrm{Na}$ primeira informação falsa, o confederado afirma que um indivíduo de casaco azul agrediu pessoas no vídeo, sendo que tal indivíduo tenta separar a briga. $\mathrm{Na}$ segunda informação falsa, o confederado afirma que existe um policial entre os agressores, porém nenhum dos agressores possui características que os classifiquem claramente como policiais.

\section{Classificação das respostas}

As respostas obtidas foram classificadas em quatro categorias: memórias verdadeiras (MV); falsas memórias espontâneas (FME) - situação em que o participante relata ter visto algo que não estava presente na cena, sem a manipulação do confederado; falsas memórias por conformidade (FMC) - memórias falsas que surgiram somente após a sugestão de falsas informações pelo confederado; e erros de observação (EO) -informações que estavam presentes na cena, mas não foram relatadas. Optou-se pela criação das categorias EO e FME, pois nem todo erro no relato dos participantes poderia ser, necessariamente, proveniente da influência social exercida pelo confederado, tendo em vista que indivíduos são naturalmente suscetíveis a cometerem erros perceptuais (Reason, 1990). Na condição concordância, os dados foram classificados comparando o questionário realizado antes da interação com o confederado e o questionário respondido após a interação, de forma que fosse possível identificar alterações nas respostas provenientes da sugestão das falsas informações.

Todas as análises foram realizadas utilizando-se as médias para cada uma das classificações de respostas (MVs, FMEs, EOs e FMCs). Também foram avaliados os erros dos participantes no geral, utilizando-se as médias de FMEs, EOs e FMCs conjuntamente.

\section{Resultados}

As primeiras análises visaram comparar o desempenho dos participantes na condição controle com os dos obtidos no primeiro questionário da condição concordância. O intuito dessas análises foi constatar a semelhança de desempenho nesses questionários, uma vez que no primeiro questionário da condição concordância ainda não havia ocorrido qualquer sugestão a informações falsas. De fato, a quantidade de memórias verdadeiras não diferiu, $t(52)=0,56, p=0,57, d=0,15$, 
tampouco a quantidade de erros, $t(52)=0,613 p=0,54$, $d=0,17$, estabelecendo uma linha de base para testar o efeito da interação com o confederado. Procedeu-se com comparações entre as respostas da condição controle e as respostas do segundo questionário da condição concordância, ou seja, após a sugestão de falsas informações. Foi observado que o número de MVs foi menor na condição concordância quando comparado com a controle, $t(52)=4,67 p<0,001$, $d=1,29$. De forma análoga, os erros foram maiores na condição concordância, $t(52)=4,96 ; p<0,001, d=1,37$. Foram comparados os dois questionários da condição concordância (antes e depois da interação), utilizando análises de medidas repetidas, a fim de verificar possíveis modificações de resposta dos participantes após a sugestão de informações falsas. Tais análises revelaram que o número de erros foi substancialmente maior, após a interação com o confederado do que antes da interação, $t(23)=4,72 ; p<0,001, d=1,97$. Estatísticas descritivas dessas análises são apresentadas na Tabela 1. Não foram encontradas diferenças nas frequências de conformidade entre os diferentes confederados $F(2,23)=1,32, p=0,29$.
Foram, também, realizadas comparações entre o desempenho para questões centrais e periféricas dos questionários, considerando, conjuntamente, o desempenho dos participantes nas duas condições. O número de MVs para questões periféricas foi maior do que a quantidade de MVs para questões centrais, $t(53)=5,98, p<0,001, d=1,40$. No mesmo sentido, foram cometidos mais erros em questões centrais quando comparados com questões periféricas, $t(53)=5,75, p<0,001, d=1,12$. Não foram encontradas diferenças significativas entre a frequência de conformidade para questões centrais e periféricas, $t(23)=1,36$, $p=0,18, d=0,41$. Estatísticas descritivas dessas análises são apresentadas na Tabela 2.

Análises descritivas dos dados apontaram que, dos 24 participantes na condição concordância apenas cinco deles $(22,9 \%)$ não se conformaram com quaisquer informações fornecidas pelo confederado, portanto 19 participantes $(77,1 \%)$ se conformaram com pelo menos uma das informações falsas. Apenas dois participantes $(4,2 \%)$ se conformaram com todas as informações falsas. De forma mais específica, 11 participantes $(45,8 \%)$ concordaram com a informação

Tabela 1. Desempenho dos participantes por tipo de resposta nas diferentes condicões experimentais.

\begin{tabular}{lccccc}
\hline & $\begin{array}{c}\text { MV } \\
\text { Média } \\
\text { (DP) }\end{array}$ & $\begin{array}{c}\text { Erros } \\
\text { Média } \\
\text { (DP) }\end{array}$ & $\begin{array}{c}\text { FME } \\
\text { Média } \\
\text { (DP) }\end{array}$ & $\begin{array}{c}\text { EO } \\
\text { Média } \\
\text { (DP) }\end{array}$ & $\begin{array}{c}\text { FMC } \\
\text { Média } \\
(\text { DP) }\end{array}$ \\
\hline Condição controle & $9,90(1,76)$ & $1,34(0,58)$ & $2,43(1,16)$ & $1,60(1,16)$ & - \\
Condição concordância - antes da interação & $9,62(1,78)$ & $1,44(0,61)$ & $2,29(1,12)$ & $2,04(1,30)$ & - \\
Condição concordância - depois da interação & $7,75(1,56)$ & $2,09(0,51)$ & $2,12(1,26)$ & $1,58(1,10)$ & $2,58(1,10)$ \\
\hline
\end{tabular}

Nota: $\mathrm{MV}=$ memórias verdadeiras; erros=somatório de todos os tipos de erro; FME=falsas memórias espontâneas; $\mathrm{EO}=$ erros de observação; $\mathrm{FMC}=$ falsas memórias por conformidade.

Tabela 2. Desempenho dos participantes no reconhecimento dos aspectos centrais e periféricos do crime.

\begin{tabular}{lcccccc}
\hline & $\begin{array}{c}\text { MV-C } \\
\text { Média } \\
\text { (DP) }\end{array}$ & $\begin{array}{c}\text { MV - P } \\
\text { Média } \\
(\mathrm{DP})\end{array}$ & $\begin{array}{c}\text { Erros - C } \\
\text { Média } \\
\text { (DP) }\end{array}$ & $\begin{array}{c}\text { Erros - P } \\
\text { Média } \\
\text { (DP) }\end{array}$ & $\begin{array}{c}\text { FMC - C } \\
\text { Média } \\
\text { (DP) }\end{array}$ & $\begin{array}{c}\text { FMC - P } \\
\text { Média } \\
\text { (DP) }\end{array}$ \\
\hline Condição controle & $4,47(1,26)$ & $5,43(1,16)$ & $0,83(0,42)$ & $0,51(0,39)$ & - & - \\
$\begin{array}{l}\text { Condição concordância - antes } \\
\text { da interação }\end{array}$ & $4,04(1,16)$ & $5,58(1,01)$ & $0,98(0,38)$ & $0,47(0,33)$ & - & - \\
$\begin{array}{l}\text { Condição concordância - Depois } \\
\text { da interação }\end{array}$ & $3,04(1,33)$ & $4,71(0,75)$ & $1,33(0,43)$ & $0,76(0,25)$ & $1,17(0,70)$ & $1,42(0,71)$ \\
\hline
\end{tabular}

Nota: $\mathrm{MV}=$ memórias verdadeiras; erros=somatório de todos os tipos de erro; $\mathrm{FMC}=$ falsas memórias por conformidade; $\mathrm{C}=$ aspectos centrais; $\mathrm{P}=$ aspectos periféricos. 
falsa de que um homem inocente estava envolvido nas agressões, e $19(79,2 \%)$ participantes concordaram em ter visto um policial entre os agressores.

\section{Discussão}

Este estudo investigou o efeito da sugestão de informações falsas na memória de testemunhas oculares. Os participantes na condição concordância eram requisitados a apresentar, juntos a um confederado, um relato unificado sobre o que se recordavam de uma cena de uma briga de rua. Em tal situação o confederado sugestionava os participantes com informações falsas. $\mathrm{Na}$ condição controle, não houve a participação de confederados, de forma que os participantes deveriam apresentar seus relatos individualmente. Os resultados obtidos revelam que a quantidade de erros cometidos pelos participantes foi substancialmente maior quando expostos a informações falsas. Uma proporção significativa de testemunhas $(79,2 \%)$ conformou com a informação equivocada de que um policial estava envolvido nas agressões, e grande parte $(45,8 \%)$ concordou com o confederado que um homem inocente estava envolvido na briga.

Os resultados obtidos neste e em outros estudos reforçam a concepção de que testemunhas oculares são facilmente suscetíveis a erros devido a efeitos de influência social e sugestionabilidade. Gabbert et al, (2003) propuseram que o efeito da conformidade na memória é resultado de um processo social, em que a informação é aceita como verdadeira em resposta à influência normativa, que decorre da necessidade de que um tem de ser aprovado por outros no contexto social (Deutsch \& Gerard, 1955). No estudo de Mori \& Mori (2008), foi verificado que a sugestão de falsas informações é mais efetiva quando a testemunha não tem nenhuma outra testemunha que suporte a sua opinião. No entanto, o nível de conformidade diminui quando ao menos outra testemunha suporta a opinião inicial do indivíduo sugestionado, situação que facilita a resistência a influências normativas.

Após assistirem a um vídeo de uma briga de rua, os participantes deste estudo tiveram um melhor desempenho para informações periféricas em comparação com as informações centrais, contrariando a hipótese inicial e resultados encontrados na literatura da área (Brown, 2003; Luna \& Migueles, 2009). É possível que tal resultado tenha sido observado como reflexo do nível de carga emocional eliciada pelo evento apresentado, de acordo com o pressuposto que a memória para informações periféricas é facilitada em eventos que possuem pouca carga emocional. Em eventos com maior carga emocional, a atenção dos observadores é voltada para os elementos que propiciam o estresse emocional, colaborando para uma melhor elaboração e processamento das informações centrais. Em situações com pouca carga emocional, a atenção é mais difusa, o que explica parcialmente o melhor desempenho para elementos periféricos, não associados com o evento central na cena. Sendo assim, é possível que o vídeo utilizado não tenha tido carga emocional suficientemente alta para gerar esse efeito, por retratar uma situação relativamente frequente nas grandes cidades brasileiras. Também não foram encontradas diferenças nas taxas de conformidade entre falsas informações centrais ou periféricas, entretanto, é necessário cautela na interpretação desse efeito, uma vez que, neste estudo, a conformidade foi comparada somente entre duas informações falsas centrais e duas periféricas.

Futuros estudos sobre conformidade entre testemunhas oculares podem se aprofundar no efeito de outras variáveis em tal fenômeno. Baron, Vandelo e Brunsman (1996), por exemplo, sinalizam que a importância que o participante atribui à tarefa que está realizando e a dificuldade da tarefa são fatores importantes na resistência a influências sociais. Em situações em que a importância da tarefa é alta e a dificuldade é baixa, a resistência à conformidade é maior. Entretanto, quando a importância da tarefa é alta e a dificuldade também é alta, indivíduos se conformam mais com informações falsas de confederados. No contexto criminal, tais variáveis são relevantes, pois existe um incentivo para que testemunhas apresentem relatos acurados, configurando uma tarefa de alta importância. Porém, muitas vezes, essas tarefas também possuem alta dificuldade, o que pode gerar maior suscetibilidade a informações falsas provenientes de outras fontes. Além disso, a pertinência da informação falsa que a testemunha recebe pode gerar maior ou menor suscetibilidade a mudanças no relato (Wright, Memon, Skagerberg, \& Gabbert, 2009). Finalmente, é relevante que outros estudos investiguem o efeito da interação entre testemunhas sem usar qualquer tipo de informação falsa, verificando, assim, de que forma a simples interação entre testemunhas pode modificar seus relat

Resultados de pesquisas como esta possuem importantes implicações práticas para o sistema criminal, sinalizando um fenômeno que deve ser, cuidadosamente, trabalhado por investigadores. Informações 
errôneas apresentadas por outras pessoas podem ser perigosamente incorporadas ao relato de testemunhas oculares. Sendo assim, a melhor solução diante de tais situações seria entrevistar testemunhas individualmente e, posteriormente, discutir as discrepâncias encontradas. Entretanto, em muitos casos é impossível para os investigadores prevenir que testemunhas tenham contato umas com as outras antes de apresentarem seus relatos. Em tais situações, os relatos de cada uma das partes devem ser avaliados com cautela, uma vez que existe a possibilidade de ocorrerem trocas de informações equivocadas entre as testemunhas.

\section{Referências}

Asch, S.E. (1951). Effects of group pressure on the modification and distortion of judgments. In $\mathrm{H}$. Guetzkow (Ed.), Groups, leadership and men (pp. 177-190). Pittsburgh, PA: Carnegie Press.

Asch, S. E. (1956). Studies of independence and conformity: A minority of one against a unanimous majority. Psychological Monographs: General and Applied, 70(9), 1-70.

Asch, S. E. (1958). Effects of group pressure upon modification and distortion of judgements. In E. E. Maccoby, T. M. Newcomb, \& E, L. Hartley (Eds.), Readings in social psychology (3rd ed., pp. 174183). New York: Holt, Rineheart \& Winston. pp. 174-183.

Baron, R. S., Vandello, J. A., \& Brunsman, B. (1996). The forgotten variable in conformity research: Impact of task importance on social influence. Journal of Personality and Social Psychology, 71, 915-927.

Bell, B. E., \& Loftus, E. F. (1989). Trivial persuasion in the courtroom: The power of (a few) minor details. Journal of Personality and Social Psychology, 56, 669-679.

Bond, R., \& Smith, P. (1996). Culture and conformity: A meta-analysis of studies using Asch's (1952b, 1956) line judgement task. Psychological Bulletin, 119, 111-137.

Brown, J. M. (2003). Eyewitness memory for arousing events: Putting things into context. Applied Cognitive Psychology, 17, 93-106.

Ceci, S. J., \& Bruck, M. (1993) Suggestibility of the child witness: A historical review and synthesis. Psychological Bulletin, 113(3), 403-439.
Christianson, S. (1992). Emotional stress and eyewitness memory: A critical review. Psychological Bulletin, 112, 284-309.

Christianson, S. A., \& Hübinette, B. (1993). Hands up! A study of witnesses' emotional reactions and memories associated with bank robberies. Applied Cognitive Psychology, 7, 365-379.

Connors, E., Lundregan, T., Miller, N., \& McEwen, T. (1996). Convicted by juries, exonerated by science: Case studies in the use of DNA evidence to establish innocence after trial. NIH Research Report: US Department of Justice.

Deutsch, M., \& Gerard, H. B. (1955). A study of normative and informational social influences upon individual judgment. Journal of Abnormal and Social Psychology, 51, 629-636

Forgas, J. P., \& Williams, K. D. (2001). Social influence: Direct and indirect processes. Philadelphia, PA: Psychological Press.

Gabbert, F., Memon, A., \& Allan, K. (2003). Memory conformity: Can eyewitness influence each other's memories for an event? Applied Cognitive Psychology, 17, 533-543.

Goodman, G. S., Tobey, A. E., Batterman-Faunce, J. M., Orcutt, H., Thomas, S., Shapiro, C., \& Sachsenmaier, T. (1998). Face-to-face confrontation: Effects of closed-circuit technology on children's eyewitness testimony and juror's decisions. Law and Human Behavior, 22, 165-203.

Hoffman, H. G., Granhag, P. A., Kwong See, S. T., \& Loftus, E. F. (2001). Social influences on realitymonitoring decisions. Memory and Cognition, 29, 394-404.

Hogg, M. A. (2010). Influence and leadership. In S. T. Fiske, D. T. Gilbert, \& G. Lindzey (Eds.), Handbook of social psychology (5th ed., vol. 2, pp. 1166-1206). New York: Wiley.

Huff, C. R., Rattner, A., \& Sagarin, E. (1996). Convicted but innocent: Wrongful conviction and public policy. London: Sage.

Ibabe, I., \& Sporer, S. L. (2004). How you ask is what you get: On the influence of question form on accuracy and confidence. Applied Cognitive Psychology, $18,711-726$.

Loftus, E. F., \& Palmer, J. C. (1974). Reconstruction of auto-mobile destruction: An example of the 
interaction between language and memory. Journal of Verbal Learning and Verbal Behavior, 13, 585-589.

Luna, K., \& Migueles, M. (2009). Acceptance and confidence of central and peripheral misinformation. Spanish Journal of Psychology 12, 2, 405-413.

Luus, C. A. E., \& Wells, G. L. (1994). The malleability of eyewitness confidence: Co-witness and perseverance effects. Journal of Applied Psychology, 79, 714-723.

Mori, H., \& Mori, K. (2008). Conformity among cowitnesses sharing same or different information about an event in experimental collaborative eyewitness testimony. Perceptual and Motor Skills, 106(1), 275-290.

Perfect, T. J., \& Lindsay, D. S. (Eds.). (2013). SAGE handbook of applied memory. London: Sage.

Pozzulo, J. D., Crescini, C., \& Panton, T. (2008). Does methodology matter in eyewitness identification research? The effect of live versus video exposure on eyewitness identification accuracy. International Journal of Law and Psychiatry, 31, 430-437.

Roediger, H. L., Meade, M. L., \& Bergman, E. T. (2001). Social contagion of memory. Psychometric Bulletin \& Review, 8, 365-371.

Stein, L. M. (2010). Falsas memórias. Porto Alegre: Artmed.

Stephenson, G. M., Clark, N. K., \& Wade, G. S. (1986). Meetings make evidence? An experimental study of collaboraive and individual recall of a simulated police interrogation. Journal of Personality and Social Psychology, 50, 1113-1122.
Warnick, D. H., \& Sanders, G. S. (1980). The effects of discussion on eyewitness accuracy. Journal of $A p$ plied Social Psychology, 10, 249-259.

Wessel, I., \& Merckelbach, H. (1994). Characteristics of traumatic memories in normal subjects. Behavioral and Cognitive Psychotherapy, 22, 315-324.

Wright, D. B., \& Davies, G. M. (1999). Eyewitness testimony. In F. T. Durso, R. S. Nickerson, R. W. Schvaneveldt, S. T. Dumais, D. S. Lindsay, \& M. T. H. Chi (Eds.), Handbook of applied cognition (pp. 789818). Chichester: Wiley.

Wright, D. B., \& Loftus, E. F. (1998). How misinformation alters memories. Journal of Experimental Child Psychology, 71, 155-164.

Wright, D. B., \& Stroud, J. N. (1998). Memory quality and misinformation for peripheral and central objects. Legal and Criminological Psychology, 3, 273-286.

Wright, D. B., Memon, A., Skagerberg, E. M., \& Gabbert, F. (2009). When eyewitnesses talk. Current Directions in Psychological Science, 18(3), 174-178.

Wright, D. B., Self, G., \& Justice, C. (2000). Memory conformity: Exploring misinformation effects when presented by another person. British Journal of Psychology, 91, 189-202.

Yarmey, A. D., \& Morris, S. (1998). The effects of discussion on eyewitness memory. Journal of Applied Social Psychology, 28, 1637-1648.

Recebido em: 02/06/2014

Reformulação em: 19/01/2015

Aprovado em: 26/01/2015 


\section{Anexo 1}

Perguntas centrais $(C)$ e periféricas $(P)$ sobre o vídeo.

1. Quantas pessoas portavam armas? (C)

2. Você viu alguma árvore? $(\mathrm{P})$

3. O homem de roupa azul agrediu alguém? (C)*

4. Você viu flores? (P)

5. Você viu sangue? (C)

6. Quantas pessoas estão brigando no início do vídeo? (C)

7. Você viu um barco? $(\mathrm{P})^{*}$

8. Você viu algum animal? $(\mathrm{P})^{*}$

9. Um policial estava presente entre os agressores? $(\mathrm{C})^{*}$

10. Você viu um banco (assento) na cena? $(\mathrm{P})$

Nota: $(\mathrm{C})=$ elementos centrais; $(\mathrm{P})=$ elementos periféricos; *perguntas para as quais o confederado fornecia informações falsas. 
Nota dos autores:

A pesquisa recebeu apoio do $\mathrm{CNPq}$ na forma de bolsa para o primeiro autor, assim como financiamento do Edital Universal CNPq (Processo número 486876/2013-6) e da FINATEC (Processo 5662) na forma de equipamentos. Os autores agradecem a Lucas Soares Caldas pela revisão crítica do manuscrito.

Sobre os autores:

Renan Benigno Saraiva é membro do Laboratório de Psicologia Social do Departamento de Psicologia Social e do Trabalho da Universidade de Brasília.

Fabio Iglesias é doutor em Psicologia, com pós-doutorado na University of Victoria, professor do Programa de Pós-Graduação em Psicologia Social, do Trabalho e das Organizações e coordenador do Laboratório de Psicologia Social da Universidade de Brasília.

Gabriel Fontenelle Micas é membro do Laboratório de Psicologia Social do Departamento de Psicologia Social e do Trabalho da Universidade de Brasília.

Clara Pires Nunes Araújo é membro do Laboratório de Psicologia Social do Departamento de Psicologia Social e do Trabalho da Universidade de Brasília.

Marcela de Vasconcelos Costa é membro do Laboratório de Psicologia Social do Departamento de Psicologia Social e do Trabalho da Universidade de Brasília.

Clara Correa Lima é membro do Laboratório de Psicologia Social do Departamento de Psicologia Social e do Trabalho da Universidade de Brasília.

Contato com os autores:

Renan Benigno Saraiva

Laboratório de Psicologia Social - Instituto de Psicologia - Universidade de Brasília Campus Universitário Darcy Ribeiro, Instituto Central de Ciências Sul - Brasília/DF.

CEP: 70900-100

E-mail: renanbsaraiva@gmail.com 